\title{
Călina MOLDOVAN \\ The Melancholy of the Machine. \\ Doubting Your Own Ghost in the Posthuman World
}

\begin{abstract}
The paper attempts to analyse several science-fiction movies with the purpose of identifying the different processes through which melancholy is depicted in the post-human cinematographic context. This topic will be further elaborated by studying how various characters that belong to the spectrum of artificial intelligence develop a complex, alien sensitivity. The research is aiming to create a better understanding of the dynamics between being human and being machine in science-fiction cinematography. Super computers, robots and cyborgs - they all seem to long after something unachievable and extremely ambiguous: the human element and this struggle generates a profound, exotic melancholy inside the machine.
\end{abstract}

Keywords: melancholy, robot, computer, cyborg, machine, science-fiction, longing, artificial intelligence.

"- Are you doubting your own ghost?

- What if a cyber-brain could generate its own ghost, create a soul by itself? What could you base your belief in yourself on then?" (Ghost in the Shell, 1995)

\section{Introduction}

The science fiction genre and its consumers have always been admirers of concepts like artificial intelligence and cyborgs, concepts that are today on the brink of becoming reality, as important technological advancements are brought into existence every day, from virtual reality and machine learning, to supercomputers and cognitive technology. We need machines as human beings as a race are biologically incapable to respond to new challenges that emerge.
Călina MOLDOVAN

Babeș-Bolyai University

calinamoldovan@yahoo.com

EKPHRASIS, 1/2019

A Melancholic Exploration of Humanity

(The Solitude of MAN)

pp. 258-269

DOI:10.24193/ekphrasis.21.19

Published First Online: 2019/06/27 
Exploration and colonization of the universe await, but Earth-adapted biological humans are ill equipped to respond to the challenge. Machines have gone farther and seen more, limited though they presently are by insect-like behavioral inflexibility. As they become smarter over the coming decades, space will be theirs. Organizations of robots of ever-increasing intelligence and sensory and motor ability will expand and transform what they occupy, working with matter, space, and time. (Moravec, 177)

In this context, the human race is confronted with a brand-new set of dilemmas, concerning morality and ethics. We are completely awed, fascinated by the possibility of man creating artificial intelligence, but we are also extremely inquisitive and analytical.

Our confusion revolves (mostly) around the social and psychological dimensions of the intelligent machines, as they are no longer simple technological advancements (or "technical artefacts"), but "agents of some sort", that take active roles (Kroes and Verbeek 1). How are they going to behave? Do they possess a conscience, a sense of self, any kind of morality? Will they develop emotions, will they be able to feel? Cinematography does actually provide us with some of the answers, it speculates and creates different possible scenarios, all orbiting around these impasses.

To state that a robot could be melancholic may, perhaps, seem far-fetched and unrealistic. However, while I was watching and examining the films for this research, I was surprised to discover that artificial intelligence not only can be, but is profoundly melancholic. It craves and longs for something so deeply unachievable, that its entire being is nothing but an unconscious yearning for the inaccessible human element. This struggle of not being whole, of being broken or flawed creates havoc inside the intelligent machine, as it is helpless and incapable of grasping human wholeness. It is, perhaps, not even aware of what it lacks.

Called today "endogenous depression" (coming from within) (Parker, "Back to Black: Why Melancholia Must Be Understood as Distinct from Depression"), melancholia flawlessly defines the machine and its struggle. Without being able to locate, pinpoint its own identity, its own sense of self, the intelligent machine feels alienated and empty, i.e. melancholic.

While analysing the movies, I was able to draw some parallels between them. There was not a movie in which the term "conscience" was not used explicitly. Other important leitmotivs found were "identity", "memory" and "fear". As the posthuman does not deal with artificial intelligence only, I am going to divide my research in three categories: super computers, cyborgs and robots.

\section{Super computers and computer-like systems}

The concept of the "posthuman" is strongly correlated with the ideas of interconnectedness and community, as the world becomes nothing but a interminable web of associations between subjects, a deleuzian rhizome that bonds together the globe. 
"In other words, to be posthuman does not mean to be indifferent to the humans. On the contrary, it rather implies a new way of combining ethical values with the well-being of an enlarged sense of community, which includes one's territorial or environmental inter-connections. This is an ethical bond of an altogether different sort from the self-interests of an individual subject, as defined along the canonical lines of classical humanism, or from the moral universalism of the Kantians and their reliance on extending human rights to all species, virtual entities and cellular compositions. (...) This process-oriented vision of the subject is capable of a universalistic reach, though it rejects moral and cognitive universalism. It expresses a grounded, partial form of accountability, based on a strong sense of collectivity and relationality, which results in a renewed claim to community and belonging by singular subjects." (Braidotti, The Posthuman 190)

In this context, we will see that the super-computers one can find in science-fiction cinematography experience this exact urge of belonging, of creating associations, even if they tend to express it in a more primitive way (which at first sight may seem violent).

In Godard's Alphaville (1965), we are presented a society governed by a sentient computer system, Alpha 60, which removed from the vocabulary of its city's inhabitants words like pluerer (to cry) or tendress (tenderness), words that are, more or less, connected with concepts like love, sadness, feelings, emotion. The citizens are not allowed to use the word "why", only "because". We can notice in the actions of this dictatorial computer that it wants to dehumanize the city's inhabitants, to transform them into machines like itself. The question one can ask oneself is whether the super computer is doing this in order to better control the people, or because it is driven by a raw need of belonging, of creating beings that are like it?

"We are unique, dreadfully unique." says Alpha 60, admitting its loneliness. It is an extremely distressing statement for a machine, which, supposedly, should not worry about these things. However, Alpha 60 does. Extremely poetic and sensitive whenever it gets the chance, the computer's voice tone is always solemn, as if every word it said were a bad omen, but at the same time it is flat and vapid. All these clues hint to a dislocated, decentralized personality, as the computer seems unable to figure out what it is lacking and why this recurring loneliness bothers it.

Going further, to Kubrick's 2001: A Space Odyssey, when first introduced to the viewer, the super-computer HAL strikes the audience as lonely and empty. Completely, brutally empty. The tone of its voice, always carrying a heavy-hearted, hopeless spirit, the smooth, lethargic moves (always a sign of depression and melancholy) and the music which accompanies its first appearance introduces to us a desolate, bleak machine. However, HAL tries to learn and understand the human nature. He does so by constantly stalking its fellow crew members. The human is to HAL worthy of study. Alien, maybe even parasitic, but worthy of research and 
investigation. HAL wants to understand Frank and David. It struggles to do so, to capture even the slightest particle of what it means to be human. This might strike the viewer as surprising, as HAL's most defining attribute is pride. Perhaps even arrogance, as HAL does not lose a single occasion to state how perfect and incapable of error it is.

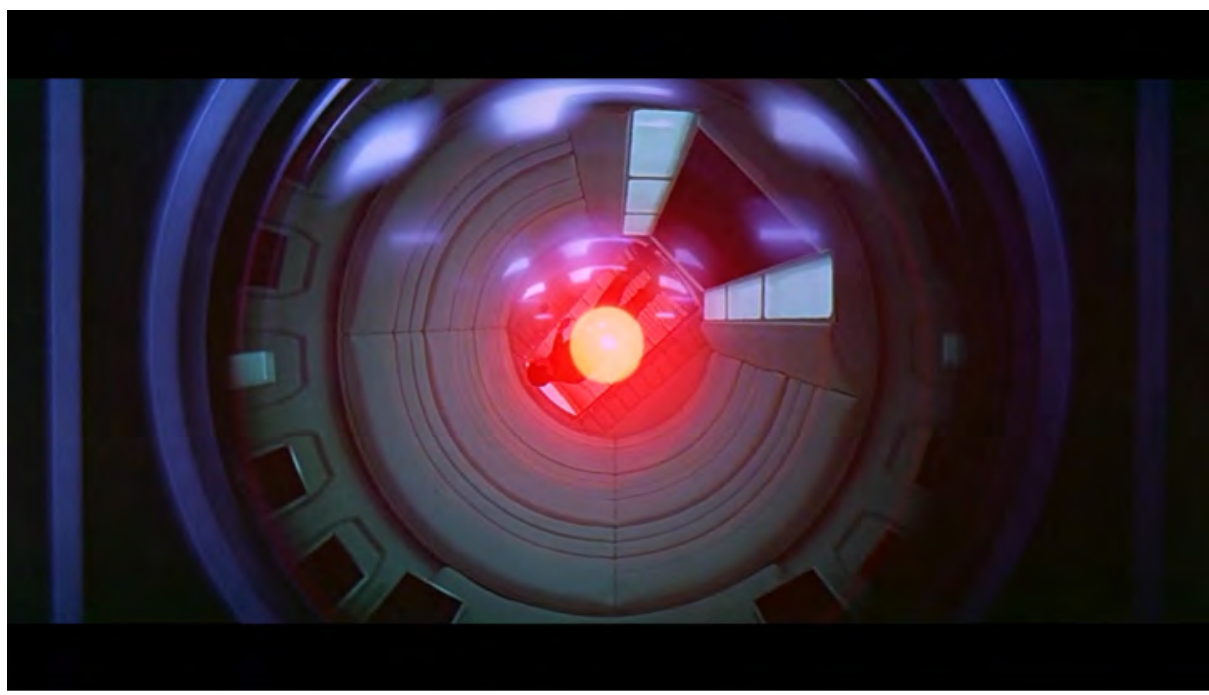

Fig.1. Kubrick, 2001: A Space Odyssey (57:30)

However, the truth is that all this pride would, perhaps, account for nothing if later (when disconnected) HAL would not have shown signs of remorse, profound fear and confusion: "I can feel it" and "I'm afraid" it says. Like a child, the computer is disoriented and frightened. This is the moment when we can draw the (perhaps surprising) conclusion that the proud HAL was nothing but a persona, that when confronted with death, HAL shows its real self.

However, neither Alpha 60, nor HAL were able to understand the real nature of their problem, as they both are incapable of comprehending the human element. They are not even aware that the detail they are blindly searching for is the aspect they are trying to suffocate, to repress. All these cinematographic details hint towards visceral aspects of melancholy (like apathy and sluggishness). Apart from them, the two super-computers are deeply empty, and where does this emptiness come from? is the question they never ask, precisely because they are unaware of it. The supercomputers experience something that is unfamiliar to them and need to adapt to the new stimulus, by "redefining" and reconsidering their values.

Becoming-posthuman consequently is a process of redefining one's sense of attachment and connection to a shared world, a territorial space: urban, social, psychic, ecological, planetary as it may be. It expresses multiple 
ecologies of belonging, while it enacts the transformation of one's sensorial and perceptual coordinates, in order to acknowledge the collective nature and outward-bound direction of what we still call the self. This is in fact a moveable assemblage within a common life-space that the subject never masters nor possesses but merely inhabits, crosses, always in a community, a pack, a group or a cluster. For posthuman theory, the subject is a transversal entity, fully immersed in and immanent to a network of non-human (animal, vegetable, viral) relations. (Braidotti, The Posthuman 193)

In Tarkovsky's Solaris (1972) the viewer is confronted with yet another system that resembles a super-computer, which is not mechanical, but organic. Described by scientists as "a gigantic cerebral system" and a "substance capable of thought processes", it might seem fair to assume that Solaris operates like a giant brain, an enormous intellect without a body, not human, but also not machine.

Solaris seems to be feeding itself out of depression, loneliness and confusion, all these representing emotions and feelings which are profoundly human and strongly correlated with melancholy. The hallucinations are created by the planet's atmosphere, but also by the symptoms of depression; consequently, these "disturbances" are created by depression and create depression (Gibarian's case, for instance). The planet's ocean "probed" the scientists' minds "and extracted something like islands of memory". It uses the men's vulnerability caused by the alien circumstances, but also by their distressing memories in order to drive them insane and create an environment it can control more easily. If everyone on Solaris feels alienated, mentally disordered and unable to find a centre, they will become part of the planet atmosphere, estranged and dislocated. The planet uses memories in order to get closer to human beings, it crawls in the scientists' brains and, entangled in their minds' complexity, steals what makes them vulnerable.

Solaris seems to be working better with powerful negative emotions such as nostalgia, while computers like Alpha 60 tries to block them. All these gigantic brains seem to undergo a constant need to communicate with humans and experience humanity, and they somehow found that negative emotion is the key. Preventing human beings to experience these emotions or augmenting their state of sadness are just two different ways of dealing with the issue. Their melancholy is a childish frustration and a quixotic struggle. They are, once again, completely dislocated and empty.

After pondering whether I should classify Khari, Kris Kelvin's wife (or her avatar, more precisely) as a robot, a cyborg or any other type of machine, I realized that she is not an individual, but she is the planet itself, its alien atmosphere incarnated. As Solaris is not human, it needs an antropomorphic facade that can make communication and connection with human beings easier. Khari is equally Solaris and Kelvin.

The most significant scene which hints towards Khari's internal discontinuity is that where she looks at herself in a broken mirror from Kelvin's room, after she looks 
at a photo of the real Khari. While holding the photo in her hands, she turns herself to look in the mirror, as if she would want to validate herself, to check if she is indeed authentic. However, the mirror is broken. The faux-Khari does not find the validation she is looking for. She is fragmented, disintegrated, defeated. Solaris cannot become human. This process may remind us of Jacques Lacan's "mirror stage", when the subject is confronted with himself, with his own "actualness". However, Khari's confrontation is not revelatory at all; the mirror does not provide her the means to develop as a future mature subject, but forces her to stop.

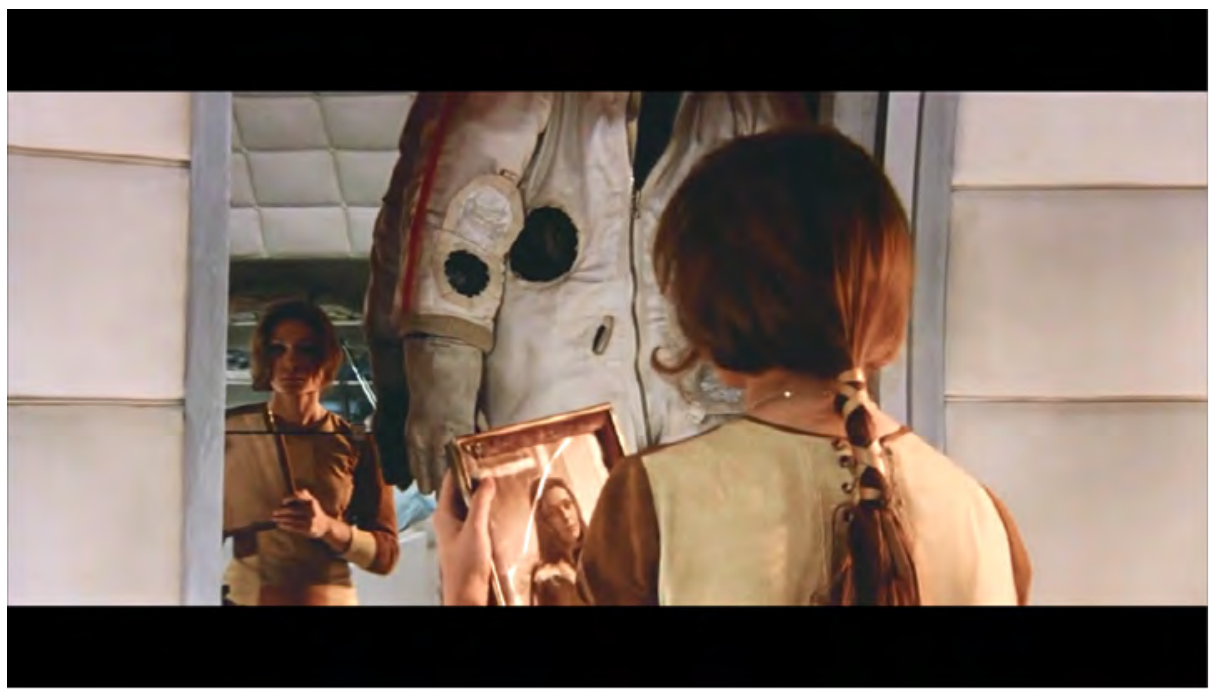

Fig. 2. Tarkovky, Solaris (01:15:50)

“- I don't know myself at all. I don't remember. When I close my eyes I can't recall my face. Do you know yourself?" the fabricated Khari asks Kevin. "Like all humans", is the psychologist's response. This scene also takes place in front of a mirror, as if Khari is always seeking reassurance that she is real and human. The melancholy she develops stems from not being able to recognise herself, as she is complete alien to humanity, but earnest to grow and evolve. We stumble upon confusion and emptiness, once again, as the attribute of being human is neither achievable nor possible to cultivate.

\section{Cyborgs and cyborg-like humans}

Going back to Godard's Alphaville, we meet secret agent Lemmy Caution, who comes to Alphaville on a mission, and Natacha von Braun, a young woman who is a citizen of Alphaville, almost completely dehumanized and rendered emotionless by the computer's system. Natacha is not precisely a cyborg, but she is more machine than human. Not physically, as she does not have mechanical body parts yet, but clearly machinelike in thinking. 
One of the most important scenes of the movie is the scene when Lemmy and Natacha discuss conscience. She reads a poem from Paul Éluard's "Capital of Pain", when she stumbles upon the word "conscience": "Il y a des mots que je ne comprends pas: conscience..."1. The ellipsis does not have enough expressive power so as to express Natacha's pure, childish confusion and disappointment (she is even struggling to pronounce the word correctly). She looks straight at the camera, which insists on further following her face, and the tone of her voice sounds as if she has reconciled herself with the idea that there are things unknown and unattainable to her. Things that she would, however, desire. Her reaction is built out of pure melancholy. She realises that there is so much more, but she is unable to determine the exact nature of this alien dimension, of this alien concept, "conscience". Natacha becomes aware of the fact that she lacks something, but, once again, she cannot determine what that is. And this, the "object-loss (humanity in Natacha's case) which is withdrawn from consciousness, in contradistinction to mourning, in which there is nothing about the loss that is unconscious" (Freud 2), is the essence of melancholy. Somatic evidence is also present in her long and slow, robot-like moves and winking, elements easily noticeable in all the close-ups.

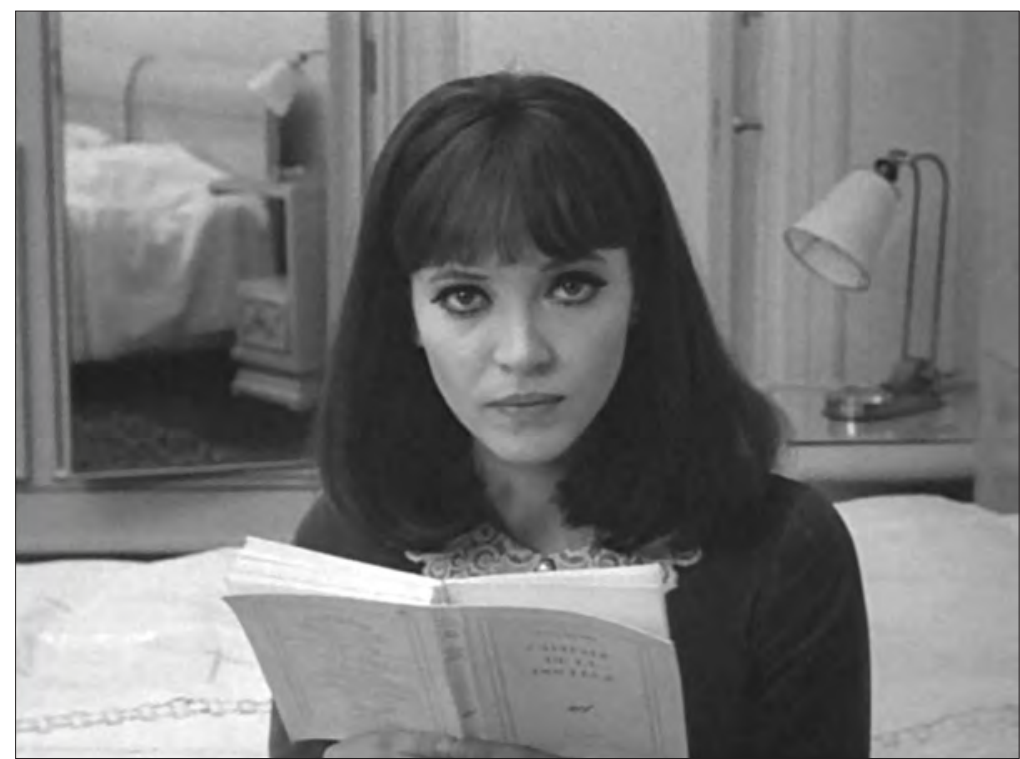

Fig. 3. Godard. Alphaville (01:06:17)

Nonetheless, the film that tackles the cyborg problem directly and more thoroughly is Ghost in the Shell (1995).

I feel fear, anxiety, isolation and darkness. Sometimes I feel hope... When I float back to the surface, I imagine I become someone else. (...) How much 
of your body is original? Man has an almost instinctive drive to realize any possible technological advances. Controlled metabolisms, computer enhanced brains, rapidly improving athleticism and reflexes, the ability to process vast amounts of information at increasing speeds, all due to electronic brains and cybernetic bodies. (...) We can quit, but we'd have to give back our cyborg parts and augmented brains to the government. All components that make up me as an individual. There are countless ingredients that make up the human body and mind. A face and voice to distinguish oneself from others, the hand you see when you wake up, your childhood memories and feelings about your future. And that's not all. There's also the ability to access vast amounts of information from an infinite network... All of that blends to create a mixture that forms me, and gives rise to my conscience. At the same time though, I feel continually confined within boundaries... (Motoko Kusanagi, Ghost in the Shell)

Ghost in the Shell deals more with the aspect of identity, than that of conscience. The phrase that best defines Motoko's struggle (because she is the character I am going to try to "figure out") is "doubting your own ghost", the phrase I also used in the title of the paper. Motoko's melancholy behaves itself a bit differently from the melancholy we have uncovered so far, and the reason for this is that Motoko is part human, part robot, consequently she understands and comprehends the human nature that is inaccessible to the aforementioned super-computers and robots.

Motoko continues her monologue further explaining the nature of her problem: the loss of her real self, of her identity and integrity as an individual: "Maybe I died a long time ago and I'm just an artificial product of a cyber-brain and a synthetic body. Maybe there was never a real me."

"To doubt your own ghost" means to doubt your own consciousness, your own existence, to doubt yourself. "What if a cyber-brain could generate its own ghost, create a soul by itself? What could you base your belief in yourself then?" Monoko finds herself in the middle of a crisis. She questions her own self and fears that she could be nothing more but matter, with a fabricated soul. She could be a fraud, or, worse, she could not exist at all as a free individual, only as a machine. This is indeed a frightful prospect.

At the beginning of the movie, when we encounter Monoko for the first time, she wakes up and looks almost confused at her own hand, slowly moving her fingers one by one, then she rubs her eyes. Her actions and the innocent confusion we can read on Monoko's expression may remind us of a newborn. She then proceeds to go near the window and stare at the world outside, with the same blank, pure, however somehow burdened and puzzled expression. As if it was her first day on earth. As if she has just been born. 


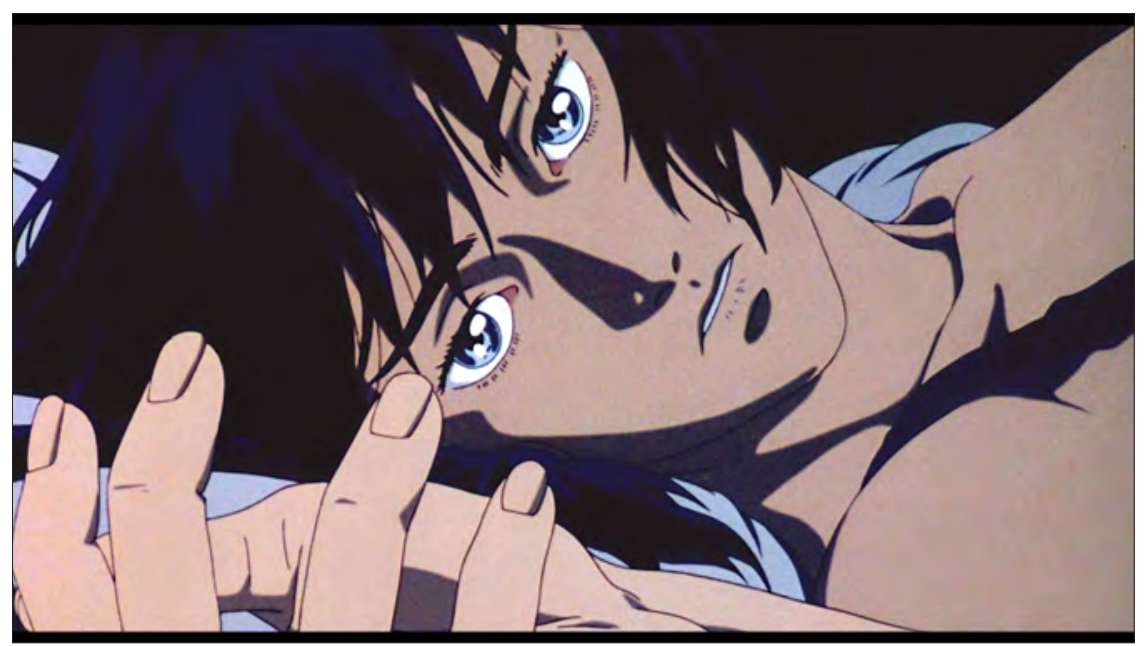

Fig. 4. Oshii. Ghost in the Shell (07:18)

If we consider the fact that later in the movie we are presented a man with false memories, who thought had a family, but it was all "in his head", we might ask ourselves if Monoko is actually a newborn. Perhaps she was manufactured, perhaps she is not even a cyborg, but a robot. These are all far-fetched assumptions, but they gradually emerge and materialize in Monoko's mind and make her doubt herself.

Donna Haraway, in her famous essay "The Cyborg Manifesto", states that "Late twentieth-century machines have made thoroughly ambiguous the difference between natural and artificial, mind and body, self-developing and externally designed, and many other distinctions that used to apply to organisms and machines." (Haraway 9). This statement contributes to the idea of a dim border between human and robot in cyborgs, but also between individualism (as a strong sense and knowledge of self) and Monoko's blurred outlook on what it means to be herself.

Monoko is always reserved and distant. She admits that the mechanical part of herself is useful and she could not live without it, as "the link between the flesh and the machine is symbiotic and therefore can best be described as a bond of mutual dependence" (Braidotti, The Politics 203).Nevertheless, she confesses that she feels "confined within boundaries". She is unable to get a sense of her identity and this horrifies and alarms her, because if this type of intrusive thoughts enter one's mind, it is incredibly hard to get rid of them. Always a symptom of mental illnesses and mental disorders (especially those concerning anxiety, but not only), the fear that you could go mad and lose your mind, your identity and the grasp you have on reality is extremely upsetting and painful. As Monoko doubts her identity, she also doubts her perspective on the world around her, and implicitly, she questions even the world she lives in. To be suspicious about whether your truth is the truth and your reality is the reality is a sign of an individual whose being has been torn apart. A decentralized self. 


\section{Robots}

In Ridley Scott's Blade Runner (1982) we meet the concept of "replicant", robots who almost perfectly copy human behaviour. Rachael is a robot of this kind, but, unlike other replicants, she is unaware of the fact that she is nothing more but a machine, a fabricated "conscience". She possesses fake memories (we also tackled this problem when we talked about Ghost in the Shell) which build her character and personality. When she is directly confronted with this issue, Rachael's first reaction is a naïve, innocent confusion. The revelation does not necessarily strike her as shocking, but it renders her disoriented and puzzled. It seems like life and vitality has left her body and she became indeed only a robot.

Conscience, identity, memory - all these three elements became completely illdefined in Rachael's new state of being: she lost her centre, her core's stability has been shattered (as her memories are, apparently, not hers), reality becomes painfully questionable and her integrity has been fractured. At the beginning of the movie, Tyrell talks about how giving replicants a past helped them be more easily controlled, more vulnerable, more human.

Rachael is an experiment, nothing more. We began to recognize in them a strange obsession. After all, they are emotionally inexperienced, with only a few years in which to store up the experiences you and I take for granted. If we gist them with a past, we create a cushion or a pillow for their emotions, then consequently we can control them better. (Eldon Tyrell, Blade Runner)

Nevertheless, in spite of all these effects Deckard's revelation had on Rachael, it is striking that her melancholy did not emerge from here. It has always been there. The robot is melancholic because it lacks something indistinguishable, untouchable. When everything became explicit and tangible, Rachael's melancholy turned into sadness, into mourning, as she did finally find out what she was lacking, a satisfaction which, for beings like HAL or Alpha 60, was unobtainable. She became aware of what she lost or of what she never possessed: humanity.

Even from the beginning of the movie, Rachael strikes us as completely lifeless. Lethargic and slow, even languid. Her lazy blinking and dreamy, introspective voice puts her, along with the other aforementioned characters, in the category of empty machines.

Katherine Hayles describes in one of her books exactly this type of melancholy that emerges from this instability of the androids and talks about a "wholeness" that cannot be achieved.

Androids are associated with unstable boundaries between self and world. The form that these associations take may be idiosyncratic, but the anxieties (...) are not. When system boundaries are defined by information flows and feedback loops rather than epidermal surfaces, the subject 
becomes a system to be assembled and disassembled rather than an entity whose organic wholeness can be assumed. (Hayles 162)

\section{Conclusion}

Melancholy is the constant struggle of a deranged subject to find the origin of his condition, to locate and understand it and, eventually, get better. However, what may seem like a clear and straightforward trajectory, is for the machine a quixotic effort. The machine will continue to endure this confusing discomfort, as identity, memory, conscience and consciousness (elements that create individuality and the self) are impossible to locate and control. This is, virtually, a malfunction.

In order to draw a conclusion let us go back to Peter Kroes and Peter-Paul Verbeek and their outlook on technical artefacts. They describe technology as a force that may easily embrace the label of "agent", which means that technological devices may take an active role in their actions (they are no longer passive undergoers). The reader is given the example of the Golem: "Although the Golem (technology) is a creation of humans, it starts to lead a life of its own, that is, to act as an autonomous agent and it is that autonomous agent." (Kroes and Verbeek 4).

Having this perspective as a background, I think it is safe to assume that, more than Kroes and Verbeek's examples (fire, a hammer and a gun), artificial intelligence can (and does) become autonomous. As the tool is beginning to mature, to learn, to experience, it develops a new sensitivity. The melancholy supercomputers, cyborgs and robots experience is theirs and theirs alone.

\section{Endnote}

1. "There are words I don't understand: conscience..."

\section{Works Cited}

Braidotti, Rosi. The Posthuman. Polity Press, 2013.

---. "The Politics of 'Life Itself' and New Ways of Dying". New Materialisms. Ontology, Agency, and Politics. Ed. Diana Coole, Ed. Samantha Frost. Duke University Press, 2010, pp. 201220

Freud, Sigmund. "Mourning and melancholia". The Standard Edition of the Complete Psychological Works of Sigmund Freud, The Hogarth Press, 2001, pp. 257-258.

Haraway, Donna J. A Cyborg Manifesto, University of Minnesota Press, 2016.

Hayles, Katherine. How we became posthuman. The University of Chicago Press, 1999

Kasdan, Margo. "Éluard, Borges, Godard: Literary dialectic in Alphaville". Symposium, vol.

30, no. 1, 1976, pp.1-13, www.academia.edu/10133761/Eluard_Borges_Godard_Literary_ Dialectic_in_Alphaville.

Kroes, Peter and Peter-Paul Verbeek. "Introduction: The Moral Status of Technical Artefacts".

The Moral Status of Technical Artefacts. Peter Kroes, Peter-Paul Verbeek (eds.). Springer Netherlands, 2014. 
Lacan, Jacques. “The Mirror Stage”. Écrits. W. W. Norton \& Company, 2002.

Moravec, Hans. "Pigs in Cyberspace", in The Transhumanist Reader. Max More, Natasha Vita-More (eds.). Wiley-Blackwell, 2013.

Parker, Gordon. "Back to black: why melancholia must be understood as distinct from depression". The Conversation, 6 Sept. 2015, theconversation.com/back-to-black-whymelancholia-must-be-understood-as-distinct-from-depression-38025. 